\title{
Un dios que sepa bailar: la performance privada, el gesto más radical*
}

A GOD WHO KNOWS HOW TO DANCE: PRIVATE PERFORMANCE, THE MOST RADICAL GESTURE

UM DEUS QUE SAIBA DANÇAR: A PERFORMANCE PRIVADA, O GESTO MAIS RADICAL

\section{Antonio Jiménez Morato**}

Cuadernos de Música, Artes Visuales y Artes Escénicas

/ Volumen 13- Número 2 / Julio - Diciembre de 2018

/ ISSN 1794-6670/ Bogotá, D.C., Colombia / pp. 15-25

Fecha de recepción: 13 de noviembre de 2017

Fecha de aceptación: 1 de abril de 2018

Disponible en línea: 6 de julio de 2018

doi 10.11144/javeriana.mavae13-2.udqs

* Artículo de reflexión. Parte de la tesis doctoral La cicatriz: cirugía y narración, Tulane University of Louisiana.

* Licenciado en Filología Hispánica por la Universidad Complutense de Madrid, Master of Fine Arts Degree in Creative Writing in Spanish por la New York

University; Master in Arts, PhD in Spanish and Portuguese Literatures por la Tulane University of Louisiana. ORCID: 0000-0002-9179-4576 


\section{Resumen}

La escritura se realiza siempre en privado. Incluso cuando tiene lugar en un entorno público nadie es consciente de estar presenciando el acto de escritura. $Y$, sin embargo, es una performance, ya que cumple con las características de una representación performática. Si no es concebida o recibida como tal, es tan solo porque no se explicita tal deseo. Este trabajo va tanteando, como una performance de danza contemporánea, esta posibilidad. Estructurado en movimientos que asemejan la estructura coreográfica de un montaje de danza, tantea hitos históricos, conceptos estéticos y filosóficos, incluso críticos, que van trenzando la relación entre la escritura y la danza contemporánea y, por extensión en última instancia, la performance. Se trata de la bitácora de la toma de consciencia de esa reverberación que se produce entre ambas disciplinas y que, posiblemente, estaba apenas esperando a ser alumbrada. El trabajo, tras el tanteo coreográfico, llega a la conclusión de que la escritura es, de todas las performances, la más radical por, precisamente, negar la necesidad del público para legitimar su existencia. La escritura es la performance de más ardua valoración, porque termina siendo invisible como tal, pese a existir. Como el concepto de infradelgado de Duchamp, uno debe admitir su existencia, incluso puede intuirla, pero no puede afirmar haberla presenciado. Esta visión de la escritura como performance privada es totalmente inédita en el campo crítico.

Palabras clave: escritura; danza contemporánea; performance; privacidad; arte conceptual; literatura.

\section{Abstract}

Writing is always done in private. Even when it takes place in a public environment, nobody is aware of being involved in the act of writing. And, nevertheless, it is a performance, since it fulfills the characteristics of a performative representation. If it is not conceived or received as such, it is only because such desire is not made explicit. This work goes probing, like a performance of contemporary dance, this possibility. Structured in movements that resemble the choreographic structure of a dance montage, it probes historical milestones, aesthetic and philosophical concepts, even critical ones, that weave the relationship between writing and contemporary dance and, by extension, ultimately, performance. This is the log of the raising of awareness of that reverberation occurring between both disciplines and that, possibly, was just waiting to be lit. The work, after the choreographic attempts, reaches the conclusion that, of all performances, writing is the most radical, precisely because it denies the need of the audience to legitimize its existence. Writing is the performance most difficult to assess, because it ends up being invisible as such, despite existing Like Duchamp's concept of Infrathin, one must admit its existence, can even intuit it, but cannot claim to have witnessed it. This vision of writing as a private performance is totally unprecedented in the critical field.

\section{Keywords: writing; contemporary dance;}

performance; privacy; conceptual art; literature.

\section{Resumo}

A escrita realiza-se sempre em privado. Mesmo quando ocorre em um ambiente público, ninguém está ciente de estar testemunhando o ato de escrever. E, no entanto, é uma per formance, pois tem as características de uma representação performativa. Se não é concebida ou recebida como tal, é somente porque esse desejo não é explicitado. Este trabalho vai provando, como uma performance de dança contemporânea, essa possibilidade. Estruturada em movimentos que se assemelham à estrutura coreográfica de uma montagem de dança, traça marcos históricos, estéticos e filosóficos, e até críticos, que tecem a relação entre a escrita e a dança contemporânea e, por extensão, a performance. Trata-se do registro da consciência dessa reverberação que ocorre entre as duas disciplinas e que, possivelmente, estava apenas esperando aflorar. Após a sondagem coreográfica, o trabalho conclui que, de todas as performances, a escrita é a mais radical, justamente porque nega a necessidade do público de legitimar sua existência. A escrita é a performance de avaliação mais difícil, porque acaba sendo invisível como tal, apesar de existir. Como o conceito de infrafino de Duchamp, é preciso admitir sua existência; é possível até intuí-la, mas não afirmar tê-la testemunhado. Essa visão da escrita como uma performance privada é totalmente sem precedentes no campo crítico.

Palavras-chave: escrita; dança contemporânea; performance; privacidade; arte conceitual; literatura. 
“No se trata todavía de sentido, no se trata de sentimiento: sino, insensiblemente, de cómo un cuerpo se desprende de sí mismo. Se deshace de su propia presencia, se descompone, se desarticula. Eso otro lo articula de otro modo, le hace hablar una lengua diferente, una lengua alterada que lo hace remontarse hacia atrás de todo lenguaje. Ese cuerpo no sabe nada de lo que ocurre: es algo que le llega desde el interior como si se tratara del más alejado de los afueras". ¿De qué habla Jean-Luc Nancy (2013) en estas líneas? Habla, desde luego, de la enajenación, del modo en que se produce el éxtasis. Pero no un éxtasis como aquel del que habló Tertuliano, en el siglo III, adaptando el ékstasis griego al pensamiento latino. Porque donde para Tertuliano, como luego para los místicos y desde allí a los que toman MDMA, se trataba, se trata aún, de abandonar el cuerpo, de dejar de ser carne, de huir de lo matérico. Pero lo que describió Nancy es cómo algo, llegado desde el interior, un interior desconocido, bárbarico, que se presenta y siente como ajeno, el más alejado de los afueras dice, se apodera del cuerpo, un cuerpo que se desprende de sí mismo, que se abandona a ese algo que desde su interior se apodera de él. Y ese proceso se acercaría más a la pasión, pasión entendida, también, en su germen etimológico, como antónimo de acción. El cuerpo sufre algo, la llegada, la acción precisamente, de eso que viene de su interior, aunque parece el más alejado de los afueras. Es curioso que pasión sea una palabra de origen latino, no griego. Muchas veces nos confundimos y pensamos que van de la mano pasión y pathos. Sobre todo cuando pensamos que sentir empatía por alguien y ser compasivo con él son casi sinónimos. Pero no lo son. El que se compadece "sufre con". Pero ¿de dónde surge ese algo que llega del interior, ese algo que, al contrario del caso de los místicos, no es algo externo que saca al alma del cuerpo, sino algo desconocido que, desde dentro, se apodera de él? Podría pensarse que pueda ser esa inspiración que es mejor recibir trabajando, el arrebato que todos han sentido cuando han tenido una idea de algo que "debían escribir". Y, sin embargo, no es de la escritura de lo que habla Nancy. Sigamos escuchándole. "Lo que insensiblemente le ocurre a ese cuerpo es que ya no forma cuerpo consigo. Adquiere holgura. Toma distancia. Comienza a pensarse. Ese cuerpo se baila, es otro el que lo baila" (288-289).

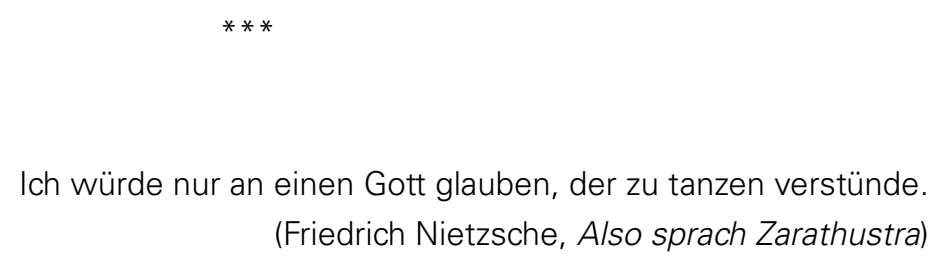

Una de las leyendas que rodean el mito de la capacidad de trabajo sobrehumana de George Simenon, una de las muchas que ha generado, tiene que ver con una performance. Una que jamás se llevó a la práctica, una que posiblemente jamás fue considerada una performance porque entonces no existía ni siquiera este concepto. A comienzos de 1927, Eugéne Merle, director de varios rotativos, se fija en el jovencísimo y fecundo Simenon para convertirlo en estrella del lanzamiento de una nueva cabecera. El autor, que contaba con menos de veinticuatro años entonces, presumía de escribir ochenta páginas al día, un capítulo por hora, trescientas líneas mecanografiadas en cuarenta y cinco minutos. ${ }^{1}$ Simenon suponía el modelo de nuevo escritor que quería Merle para París-Matin, su nuevo 
periódico populista, y a cambio de una cuantiosa suma como remuneración le propone una performance, aunque ellos, ni Merle ni el propio Simenon, llegaron a saber, como ya se ha dicho, que lo era: escribir una novela a lo largo de una semana encerrado en una jaula de cristal a la vista del público. El proyecto del periódico se vino abajo antes de ser lanzado y la performance nunca llegó a tener lugar. Pero el mito creció con el paso de los años, entre otras cosas, porque Simenon y su esposa explicaron en varias ocasiones cómo escribía sus novelas, y que siempre respetó el plazo de una semana para realizarlas. Una semana planificada, en la que la mujer se encargaba de que el retiro monacal fuera seguido a rajatabla y todas las necesidades logísticas cubiertas para lograr la producción del nuevo producto. Este proceso se repetía unas cuatro veces por año, sistemáticamente, del mismo modo que Simenon escribía, del mismo modo en que sus lectores lo devoran hoy: por sistema, por rutina, religiosamente. Muchos afirman que Gallimard lo convenció para llevar a cabo la idea primigenia en el escaparate de la sede parisina de su editorial. Algunos, incluso, afirman haber visto a Simenon escribiendo en ese escaparate. Pero no hay un solo documento que lo pruebe. Una performance que jamás ha llegado a tener lugar, el "no va más" del esnobismo o lo más brillante que alguien pueda imaginar. Desde luego, hasta en eso Simenon se presenta hoy como un visionario. Pero, sobre todo, conviene no olvidar el corazón mismo de la idea: lo novedoso, lo sorprendente, no es que alguien escriba velozmente, sino que lo haga en público, porque la escritura, por regla general, ha sucedido siempre en privado. Más allá de la existencia o no de la performance de escribir en el escaparate del periódico, lo que, involuntariamente, Simenon y Merle vinieron a apuntar es que en todo acto de escritura hay una performance. Una, eso sí, sin un público en el sentido escénico del término.

\section{$* * *$ \\ If I could tell you what it meant, there would be no point in dancing it. (Isadora Duncan, Isadora Speaks...)}

Basta una búsqueda en Google para comprobar que un video de diez segundos donde se ve a Isadora Duncan moverse ha sido contemplado cientos de miles de veces, no sé si por lo que tiene de fascinante o por tratarse de un documento único. Posiblemente por ambos motivos: como bien supo intuir Walter Benjamin (2017), toda foto, y por extensión toda película de celuloide, termina concentrando en sí una cantidad tan ingente de aura que hace sobrecogedora su contemplación. Paradójicamente, el arte reproducido en grandes cantidades desaguó el aura de la creación artística, pero la democratización de los medios necesarios para el registro de la realidad sufrió un proceso inverso. Conectarse a Instagram puede ser hoy más satisfactorio estéticamente que visitar muchos museos. En todo caso, la mítica bailarina ${ }^{2}$ dejó un ramillete de citas fascinantes para explicar su relación con la danza. Lejos de ver una paradoja en la cita a la vista de su fecunda escritura, viene a reforzar la idea de que la danza, el movimiento, explora otras realidades, otros espacios, que los investigados por la palabra. La propia Duncan (1972) señaló, también, que "movements are as eloquent as words" (los movimientos son tan elocuentes como las palabras) (343). No 
más ni menos, sino "tan". Y posiblemente rodean, investigan, la misma realidad que nos hemos acostumbrado a tantear con el lenguaje, pero lo hacen de un modo muy diferente. Un modo inefable, de ahí lo escurridizo de toda aproximación verbal, intelectualizada, a sus procedimientos y logros. De todas sus frases, en todo caso, prefiero cuando afirmó que "ella podía bailar ese sillón". No describirlo, no usarlo, no recostarse en él o pensar desde él, no nombrarlo. Bailarlo. Y al usar ese verbo, performativo hasta lo inamovible, porque cuando alguien dice que baila algo se nos aparece ya de por sí en movimiento, trazando una coreografía espontánea, puede inducir al engaño, al error. Tendemos a pensar que en ese momento el danzante produce una realidad distinta de aquello que quería explorar, el sillón, por ejemplo, y eso es porque asociamos la danza a una creación artística. No sucede lo mismo con la escritura. Concebimos un mundo abarrotado de textos no literarios, pero no pensamos que, en el movimiento de un danzante, voy a rehusar el término bailarín, que parece relacionarse más con una profesión, pudiera ser algo diferente de un proceso artístico. No hay nada que justifique la relación intrínseca entre danza y representación que hemos automatizado. Isadora Duncan escribió ${ }^{3}$ mucho sobre el hecho de que sus movimientos, sus coreografías, sus piezas, pretendían algo muy cercano a su escritura, pero transitaban por senderos donde el significado de las palabras, los conceptos que tanteamos con el lenguaje, se presentan fatalmente inoperantes.

Die Hand ist das Fenster zum Geist. (Immanuel Kant)

“La mano es la ventana a la mente", escribió Kant. Nos hemos acostumbrado tanto a la virtualidad del mundo, a la construcción de estructuras conceptuales en las que realmente vivimos, aunque no queramos reconocerlo, que nos olvidamos de que en realidad el mundo lo hemos hecho con las manos. La mitología judeocristiana es explícita a ese respecto: Dios amasó el barro con el que hizo a Adán. Y con una de sus costillas hizo a Eva. Por eso, Flannery O'Connor (2009), posiblemente la escritora más obsesionada con la ponderación de las palabras de Dios, de la Biblia, que vivió aterrorizada ante la posibilidad de que el lupus eritematoso sistémico que la mató tan joven fuera el síntoma evidente de que no gozaba de la gracia del Señor, no dudaba a la hora de establecer una identificación directa entre el narrador, que crea materia, y la obra divina. Y por eso afirmaba que ambos trabajan con sus manos hasta ensuciárselas, dejando los conceptos en el terreno de los teólogos o los filósofos. Lo curioso es que la escritura, independiente de aquello que se vehicula a través de ella, es en sí una actividad manual. Puede no serlo el lenguaje, su oralidad lo relaciona con otro espacio anatómico, pero la escritura sí requiere un gesto de la mano. Sea con el punzón, con la pluma o el lápiz o con los dedos bailando sobre un teclado, el acto de la escritura se ha hecho siempre con las manos. ${ }^{4}$ El más Ilamativo sea quizá el lenguaje manual de los sordos, que crearon el más bello sistema coreográfico para comunicarse. No, no es una ocurrencia mía, basta con conocer el trabajo de Pina Bausch para darse cuenta de que me limito a citarla de modo indirecto. A bailarla. La escritura es, pues, una danza. Llena de 
arrepentimientos, de errores, es a través de ese avance y retroceso, de esos saltos y cambios de dirección, como se construye pensamiento. Heinrich von Kleist (1984) lo plasmó de modo magistral en Sämtliche Erzählungen und andere Prosa (Acerca de la elaboración de las ideas en el discurso). Algo parecido, con su código particular, hace Viveca Vázquez para construir sus obras: como el escritor parte de balbuceos, y en ellos encuentra primero palabras, luego frases y, finalmente, ideas. Al ensamblarlas obtiene sus coreografías. La danza subyace en todo trabajo, a veces disimulada, para que apenas sea percibido el ritmo, en todos intencionada, fuerte, marcada, para que se hagan más evidentes cada uno de los pasos de la coreografía. Pienso en Saer y La mayor, donde a la coreografía de la escritura le sucede la de la lectura, que se desliza por las líneas con un ritmo casi tangible:

Otros, ellos, antes, podían. Mojaban, despacio, en la cocina, en el atardecer, en el invierno, la galletita, sopando, y subían, después, la mano, de un solo movimiento, a la boca, mordían y dejaban, durante un momento, la pasta azucarada sobre la punta de la lengua, para que subiese, desde ella, de su disolución, como un relente, el recuerdo, masticaban despacio y estaban de golpe ahora, fuera de sí, en otro lugar, conservando mientras hubiese, en primer lugar, la lengua, la galletita, el té que humea, los años: mojaban, en la cocina, en invierno, la galletita en la taza de té, y sabían inmediatamente, al probar, que estaban llenos, dentro de algo y trayendo, dentro, algo, que había, en otros años, porque había años, dejado, fuera, en el mundo, algo, que se podía, de una u otra manera, por decir así, recuperar, y que había, por lo tanto, en alguna parte, lo que llamaban o lo que creían que debía ser, ¿no es cierto?, un mundo. $(1976,9)$

Trägt doch der Tänzer sein Ohr-in seinen Zehen! (Friedrich Nietzsche, Also sprach Zarathustra)

Las dos artes durativas por excelencia son la música y la literatura. No pueden ser percibidas de modo absoluto y simultáneo. El danzante, repito, no el bailarín, sino un danzante cualquiera, se introduce dentro de esa temporalidad y, para hacerlo, se deja llevar por los golpes del ritmo. Por eso, Nietzsche (1998) afirmaba que "el bailarín tiene su oído en los dedos de los pies" (231). La performance primigenia, que nace de la danza contemporánea, puede ser interpretada por un espectador inexperto, pero atento como "una danza sin música". El performer, el actuante, se mueve, realiza gestos cuidadosamente planificados, incluso coreografiados, pero sin una música que los albergue. A veces las performances se complican al introducir una banda de sonido que aparece intencionadamente disociada de los movimientos del actuante. Al mismo tiempo, la representación —el espectador novato no distingue aún entre representación y performance- tiene una duración determinada, como sucede en el caso de un ballet. El danzante, el actuante, sigue patrones que el espectador desconoce y eso lo invita a encontrarlos, a descifrarlos. Una de las grandes virtudes de la performance es que incomoda al espectador acostumbrado a ser dirigido de modo 
totalmente pasivo. Se siente así inducido a participar en la obra. No basta con presenciarla como espectador, hay que involucrarse en ella, interpretarla, montarla, dotarla de un sentido. Lo mismo sucede con la escritura. No ya el trabajo, algo que es obvio y se ha estudiado, sino con el gesto de la escritura. Buena muestra de ello es que el hombre no puede dejar de hacer garabatos, firmar, escribir cualquier cosa, cuando tiene un instrumento de escritura y una superficie donde hacerlo. Hay algo que lo impele, como al danzante, a dejarse llevar. Por eso, la escritura es en sí performativa, genera sentido de modo espontáneo, sin que ni siquiera quien la usa sea consciente de ello. Una plusvalía inconsciente e inesperada, que a veces se convierte en literatura. En El discurso vacío, Mario Levrero (2014) plantea una hipotética terapia conductista que sigue el narrador y protagonista de la novela: escribir textos carentes de discurso, en los que tan solo se pretenda ejecutar la coreografía caligráfica del modo más perfecto posible. La idea es que, si logra disciplinar su mano para trazar esa caligrafía de pendolista que anhela lograr, podrá vehicular ese proceso correctivo en una sanación para todo su organismo. Pero cuando llega la hora de ejecutar esos ejercicios se percata de que es casi imposible conservar la intención de centrarse en el trazado de la escritura. Pronto aparecen a borbotones temas, obsesiones solapadas antes y emergidas del inconsciente que echan por tierra el perfecto acabado de la página. La letra se torna deforme, fea, abigarrada, pero en ella florece el sentido. El acto de escribir genera sus significados de modo autónomo, porque es automático, irreflexivo, como el danzar.

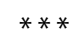

Music rots when it gets too far from the dance. Poetry atrophies when it gets too far from music.

(Ezra Pound, $A B C$ of Reading)

En Boutès, Pascal Quignard (2008) pondera, entre otras cosas, los tres modos en que el hombre se enfrentó a las sirenas en el mito griego. Tan solo tres hombres se relacionaron con el canto de las sirenas -esas mujeres-pájaro en origen que más tarde se convirtieron en mujeres-pez por extraños azares- y el modo en que lo hicieron fue muy diferente. El primero de ellos, Orfeo, logró tapar con su canto el de las sirenas y así evitó que los Argonautas encallaran su nave en los acantilados que las albergaban. Quignard ve en Orfeo, que desoye, oculta, el canto de las sirenas, lo cubre con su propio canto, la voluntad de no permitir que el canto ni siquiera exista, acallarlo como modo de no verse tentado por él. El segundo es Ulises. Conocedor del mito de Jasón, quiere escuchar el canto de las sirenas y poder más tarde relatar su peripecia. Por eso, distribuye tapones de cera entre todos los marineros de su barco y les pide que lo aten al mástil para que no se lance subyugado por la borda al escuchar a las sirenas. Quignard relaciona el modo en que Odiseo escucha el canto con la actitud de los espectadores de los conciertos, en especial los de música culta. Quietos, impertérritos, escuchan íntegras las piezas que el ejecutante desgrana sin que pueda haber un gesto, un solo movimiento que delate un nivel de recepción que se salga de lo mental, lo intelectual, dominado por las férreas cadenas de la razón que inmovilizan al cuerpo. La música, que carece de mensaje verbalizable, convertida en actividad intelectual. 
Pero hay un tercero, Butes, que ha quedado olvidado, ¿por qué? Porque Butes, que es uno de los Argonautas, sí salta del barco para seguir el canto de las sirenas. Es quien se arroja al escuchar la música, quien se sumerge en ella. Quien se suelta a danzar. Por eso, pese a que todo parece indicar que es el condenado, en realidad se libera, y por eso mismo es salvado por Cipris (Afrodita) a quien fecundará y con la que tendrá dos hijos. ¿Por qué nada sabemos de Butes? Porque él supo escuchar, vencer esas cadenas y dejarse mecer por la música de las sirenas. Él fecundó a Afrodita, la diosa del saber. Él bailó.

A writer's biography is in his twists of language. (Joseph Brodsky, Less Than One)

En Espectáculos de realidad, Reinaldo Laddaga (2007) apostaba una teoría interesante, la de que hay toda una línea dentro de la literatura latinoamericana actual en la que los autores se dedican a estructurar sus libros como performances de escritura. Laddaga cree que la intención última es convencer al lector de la simultaneidad del proceso de escritura con el de lectura, "el lector lee la escritura" literalmente, y así hace que los procedimientos editoriales se adelgacen hasta hacerlos desaparecer del proceso comunicativo de todo trabajo. Es una teoría más que interesante, que va rastreando en la obra de Severo Sarduy, Reinaldo Arenas, Fernando Vallejo, João Gilberto Noll, Osvaldo Lamborghini, César Aira y Mario Bellatin. Resulta muy refrescante para comprender una de las líneas de tensión de la escritura actual. Quizá habría sido todavía más interesante haberse atrevido a buscar ecos para ese comportamiento en otras literaturas, no con la misma densidad analítica, pero sí como evidencia de que el fenómeno no es insular, no se está dando tan solo dentro de un determinado espacio. No es excesivamente complicado: Gordon Lish en la norteamericana, por ejemplo, Dominique Fabre en la francesa, Ugo Cornia en la italiana, etc. O sea, lejos de una ocurrencia, Laddaga ha sabido fijar y detener la mirada en un proceso real del fenómeno discursivo, que puede encontrar nuevas interpretaciones en la desaparición del tejido editorial clásico o el desarrollo de nuevos espectáculos como las improvisaciones de escritura en público. Sesiones donde lo que se hacía en privado se exhibe, casi pornográficamente, para un público ávido de esa porción de intimidad. Pero, si uno recapacita al respecto, emerge una respuesta clara y potente: lo que se está produciendo es la aparición en la superficie denotativa, en el acabado final del trabajo, del proceso que todo autor sigue en su escritura. Tras todo trabajo hay una performance, una coreografía que, eso sí, durante siglos ha sido algo privado o clandestino. Ahora los escritores lo muestran, hay en esos autores de los que Laddaga habla una cierta vocación exhibicionista. Hay algo que esté emergiendo. Eso a lo que se refiere Brodsky (1987) cuando habla de "los giros" del lenguaje, que durante tanto tiempo se entendió de modo banal, dentro de la estética barroquizante y retoricista que postulaba la idea de la literatura como un discurso artificioso y culto, estéticamente integrado dentro de esa cosa cursi que los franceses llamaron les belles lettres, y que hoy tiene una apariencia no ya antigua o anacrónica, sino que parece directamente 
material extraído de una excavación arqueológica. No, esos giros, esas piruetas a las que se refiere Brodsky, son exactamente los mismos movimientos que el danzante realiza para escribir su trabajo. Leamos literalmente la poesía y dejémonos de tanta metáfora. Toda escritura es, necesariamente, performativa y, por extensión, es una performance. Volvamos a Levrero y los ejercicios, primero caligráficos y luego sencillamente grafías, que sirven como disparadero de El discurso vacío, donde se nos cuenta sus esfuerzos por trazar una K manuscrita. ¿No es un ejercicio coreográfico ser capaz de escribir manualmente hoy? Haga la prueba, mi semejante, mi hermano, escriba una B mayúscula sin levantar la pluma del papel. En algunos escritores, y Mario Bellatin (2012) sería en ese sentido una figura importantísima para entender las tensiones que esta concepción emergente genera, porque él las ha sentido siempre en su escritura y en la constitución de su personaje público, de ahí la disparidad de proyectos paralelos, propuestas vanguardistas, reflexiones estéticas, intervenciones artísticas, que ha realizado y de las que luego se ha nutrido para narrarlas, reflexionar sobre ellas e incluso mitificarlas en su obra escrita. Si la Documenta de Kassel lo ha invitado como artista no es tan solo por las singularidades de su obra literaria, sino por la capacidad que ha demostrado de desbordar los límites, más estrechos de lo que nos gusta pensar, de la práctica literaria. Pero, al mismo tiempo, en esa búsqueda casi desesperada, en esa neurosis de la esencia del creador en la que él se ha embarcado, uno tiende a pensar que ha olvidado, o había, porque de hace unos años a ahora ha retornado a la producción literaria con redoblado afán, que el gesto más radical es sencillamente el de la escritura. Bellatin, decía y no es gratuito recordarlo, tiene un brazo atrofiado. Normalmente lo lleva oculto y a veces muestra unas prótesis. Quizá por eso es el autor que de forma más patente explicita el origen manual de la escritura. La presencia fantasmática de esa mano la hace más patente. Incluso hoy, cuando uno puede dictar a las máquinas, Bellatin sigue usando la mano como herramienta de escritura. Porque, como él recuerda cada vez que toca el tema, si no se hace con la mano no es escritura. Es un arte, todavía hoy, corporal, que sigue un ritmo, que es, pues, danza. Y es tremendamente radical, más intenso aún que la danza, porque se produce a puerta cerrada. Todo escritor desarrolla una serie de gestos, de movimientos, destinados a buscar, entender, narrarse, ponderar, cuestionar, expresar, etc., su entorno. Del mismo modo que lo hace el actuante. Pero, mientras el actuante, y en particular la práctica de la performance como tal, parecen requerir un espacio compartido y un público, la escritura no lo requiere. O no lo ha requerido a lo largo de su historia. La escritura es, pues, conviene recordarlo, no un sencillo gesto íntimo, sino una performance privada, que cumple con muchos de los requerimientos de las performances artísticas. Por ejemplo, deja un registro - el trabajo - como muchas veces lo hace la performance con una grabación audiovisual; un registro que requiere, sí, un cómplice que lo desentrañe, que lo ejecute, momento en que se completa. Pero la producción y la recepción no necesitan ser simultáneas, no exigen un espacio compartido, como sí lo hace la performance. Por eso, es la escritura el gesto más radical, de ahí que la escritura sea la posibilidad más extrema de performance, aquella que, en realidad, se hace sin confiar en la presencia de destinatario alguno. Como mensaje que sale al mar dentro de una botella. La escritura no necesita de receptor, la escritura es radical porque desmonta el esquema de todo acto de comunicación, pese a que parece reafirmarlo lo desmonta, lo desactiva, va más allá de cuestionarlo para reventarlo por dentro, ya que niega el lugar del receptor, que pasa a tener 
una función 0 en el esquema del acto de la escritura. La escritura es, de hecho, un ejercicio de falta de pudor, de exhibición de lo realizado de modo íntimo, cerrado, reservado, prohibido. Podría ser casi obsceno, y acaso por eso se realice en privado. La escritura es privada, no así la publicación que es exhibicionista. Barthes afirmó que,

cuando más me expongo es, en efecto, cuando divulgo mi privacidad: no por peligro de "escándalo", sino porque en ese caso presento mi imaginario en su consistencia más fuerte; y lo imaginario es eso mismo sobre lo que los otros tienen poder: lo que no cuenta con la protección de ningún vuelco, ninguna dislocación. (2018, 111-112)

\section{NOTAS}

1 La gran traba de Simenon para ser considerado algo más que un entretenido, rentable y enriquecido escritor en su tiempo fue esa obsesión cuantitativa, de apariencia tan vulgar entonces. Quizá en el mundo del capitalismo tardío esa se haya convertido en su principal virtud, y por eso ahora no se la menciona nunca y se lo expone tan solo como un gran literato, pese a que los criterios estéticos no se hayan modificado de manera tan radical como para justificar su acceso al parnaso literario. Algo parecido viene sucediendo con Stefan Zweig, con Sándor Márai o con Somerset Maugham, autores que el ultracapitalismo actual idolatra sin reconocer por qué: su trazabilidad económica.

2 Usaré mucho ese adjetivo, mítico, a lo largo de este trabajo montado como una coreografía hecha de fragmentos, de tanteos, porque, si hay algo que la performance no ha perdido del baile, es su capacidad de servir como vehículo para entrar en contacto con el mito.

3 Lo que provoca una nueva paradoja, porque hoy nos vemos citando su pensamiento a través de sus palabras y no de sus bailes.

4 Ni siquiera los avances tecnológicos, como los que permiten a discapacitados como Stephen Hawking -ironías del lenguaje - interactuar con su entorno, dejan de estar diseñados y hechos con la mano.

\section{REFERENCIAS}

Barthes, Roland. 2018. Roland Barthes por Roland Barthes. Buenos Aires: Eterna Cadencia.

Bellatin, Mario. 2012. 100 Notes-100 Thoughts/100 Notizen-100 Gedanken (Book 18). Kassel: Hatje Cantz. Benjamin, Walter. 2017. La obra de arte en la era de su reproductibilidad técnica. Galisteo: La Moderna.

Brodsky, Joseph. 1987. Less than One. Nueva York: Farrar, Straus and Giroux.

Duncan, Isadora. 1972. My Life. New York: Liveright.

- 1981. Isadora Speaks: Uncollected Writings and Speeches of Isadora Duncan. San Francisco: City Light Books.

Kleist, Heinrich von. 1984. Sämtliche Erzählungen und andere Prosa. Stuttgart: Reclam. 
Laddaga, Reinaldo. 2007. Espectáculos de realidad. Rosario: Beatriz Viterbo.

Levrero, Mario. 2014. El discurso vacío. Buenos Aires: Random House.

Nancy, Jean-Luc. 2013. La partición de las artes. Valencia: Pre-Textos.

Nietzsche, Friedrich. 1978. Also sprach Zarathustra. Ditzingnen: Reclam Verlag.

- 1998. El nacimiento de la tragedia. Madrid: Edaf.

O'Connor, Flannery. 2009. Mistery and Manners. Nueva York: Farrar, Strauss and Giroux.

Pound, Ezra. 2010. The ABC of Reading. Nueva York: New Directions.

Quignard, Pascal. 2008. Boutès. París: Galilée.

Saer, Juan José. 1976. La mayor. Buenos Aires: Planeta.

\section{Cómo citar:}

Jiménez Morato, Antonio. 2018. "Un dios que sepa bailar: la performance privada, el gesto más radical." Cuadernos de Música, Artes Visuales y Artes Escénicas 13 (2): 15-25. http://doi.org/10.11144/javeriana.mavae13-2.udqs 